\title{
STUDIES ON THE SANDFLY FAUNA OF SAMUEL ECOLOGICAL STATION, PORTO VELHO MUNICIPALITY, RONDÔNIA STATE, BRAZIL
}

\author{
ALFREDO C. R. AZEVEDO; SÉRGIO L. BESSA LUZ; MAURÍCIO L. VILELA \& \\ ELIZABETH F. RANGEL
}

\begin{abstract}
Departamento de Entomologia, Instituto Oswaldo Cruz, Av. Brasil, 4365, 21045-900 Rio de Janeiro, RJ, Brasil
\end{abstract}
In a study of sandfly species in the Samuel Ecological Station, in Porto Velho, Rondonia State, the following species were identified: Lutzomyia braziliensis, L. evangelistai, L. gomezi, L. anduzei, L. flaviscutellata, L. richardwardi, L. shawi, L. umbratilis, L. yuilli yuilli, L. dendrophyla, L. puctigeniculata, L. shannoni, L. amazonensis, L. ayrozai, L. carrerai carrerai, L. claustrei, $\mathrm{L}$. davisi and $\mathrm{L}$. lainsoni.

L. richardwardi, L. umbratilis and L. c. carrerai were the predominant species captured of man forming $60.3 \%$, of the tolal catch. L. richarwardi was the most frequent at ground level $(29.9 \%)$, while L. umbratilis predominated in the canopy $(48.5 \%)$.

Key words: Sandfly fauna - Lutzomyia - Rondônia State

American cutaneous leishmaniasis (ACL) has been considered as one of the major parasitic diseases occurring in the Amazonian region (Eletronorte, 1990). In Central Amazônia, ACL is a zoonosis caused by Leishmania (V.) guyanensis, which is transmitted by Lutzomyia umbratilis (Lainson et al., 1979). L. whitmani and $L$. anduzei have been considered as secondary vectors, maintaining the transmission among silvatic mammals (Lainson, 1983).

As with much of the Amzonian region, Rondônia State has been settled recently because of national economic pressures. The disease in this region is an occupational hazard and it is related to colonization.

With the objective of amplifying knowledge of the sandfly fauna of Northewestern Brazil, the present paper reports a study of sandfly species captured in the Samuel Ecological Station, Rondônia State.

\section{MATERIALS AND METHODS}

Study area - The Samuel Ecological Sta-

Work supported by ELETRONORTE (RO and DF); FUNASA (RO) and CNPq grant no. 40.0649/89.6

Received 5 April 1993.

Accepted 26 July 1993. tion has 28.865 ha and it is located in Porto Velho Municipality $\left(8^{\circ} 50^{\prime}-9^{\circ} 04^{\prime} \mathrm{S}\right.$ and $63^{\circ} 08^{\prime}$ $-63^{\circ} 19^{\prime} \mathrm{W}$ ). It is bounded to the north and east by the Gleba Jacundá, to the south by Jamari National Forest, and to the west by the Jamari river (Fig.). This is an area of "Tropical Forest" and the predominant vegetation type is "floresta densa de terra firme".

Meteorological data - It has a tropical wet hot climate, with three dry months (June-August) and four very rainy months (DecemberMarch).

According to more recent data (Eletronorte/ Sondotécnica, 1988) the annual rainfall was $2,010-2,950 \mathrm{~mm}$; the average temperature ranged between $24.8{ }^{\circ} \mathrm{C}-26.3^{\circ} \mathrm{C}$; the relative humidity was $74.2-90.2 \%$.

Mammal fauna - According to Eletronorte/ Sondotécnica (1988) there are 33 types of mammals in the region; some of them could be Leishmania reservoirs.

Sandfly captures - During October/November/December 1990 and May/June/July 1991, captures were performed daily between 6 p.m. and 8 p.m., using a manual aspirator. Sandflies that bit man, were caught simultaneously at ground level and at $20 \mathrm{~m}$ above ground level, in the canopy. 


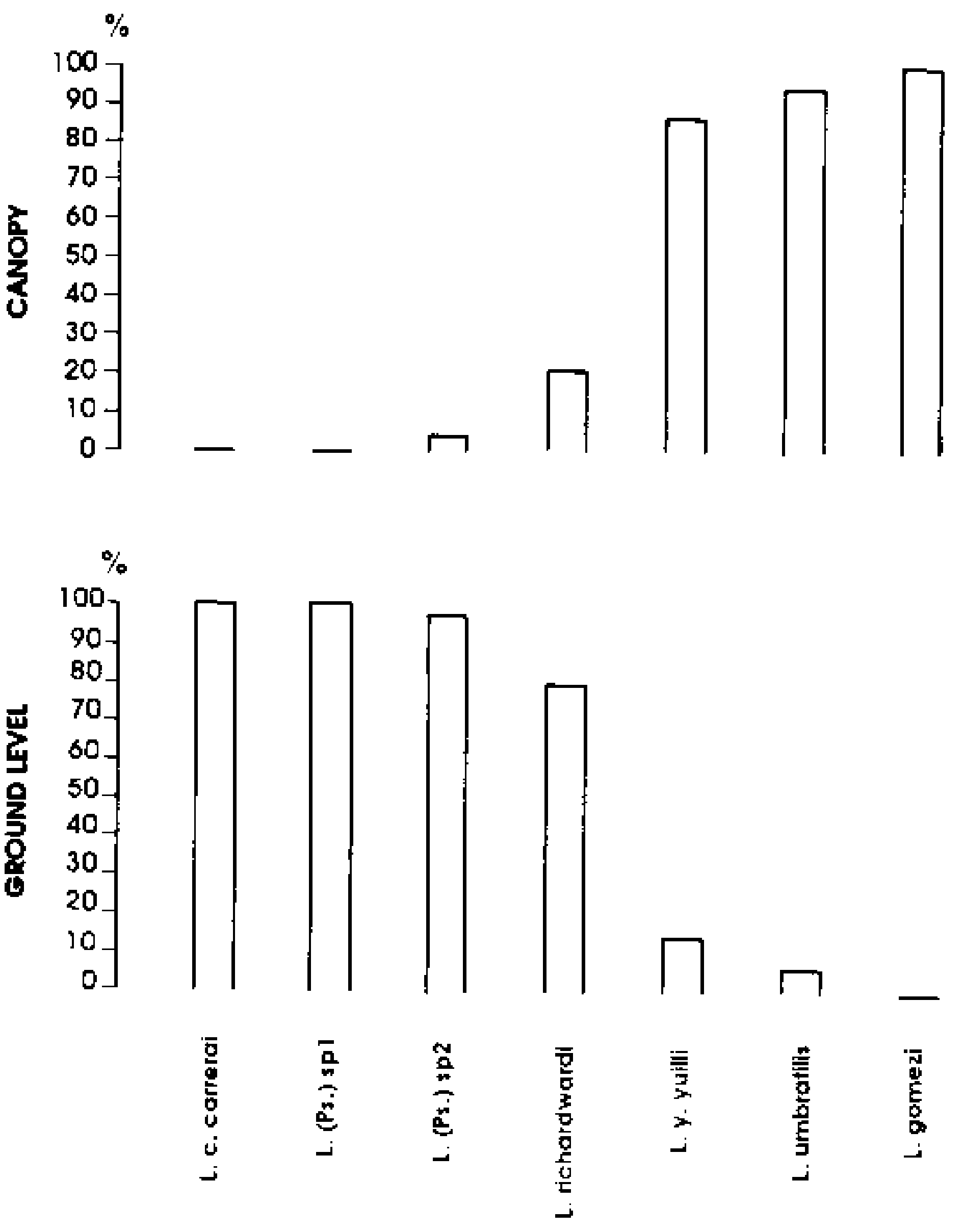

Stratification of sandflies collected on human bait in Samuel Ecological Station, in Porto Velho Municipality, Rondônia State. October-December 1990 and MayJuly 1991 .

\section{RESULTS}

Sandfly fauna - A total of 1,143 sandflies were captured in $112 \mathrm{hr}$ of which $99.73 \%$ were females. According to the classification given by Young \& Ducan (1992), the following species were found:

Subgenus Psychodopygus Mangabeira, 1941 Lutzomyia amazonensis (Root, 1934)

L. ayrozai (Barretto \& Coutinho, 1940)

L. carrerai carrerai (Barreto, 1946) 1979

L. claustrei Abonnenc, Lèger \& Fauran,

L. davisi (Root, 1934)

L. lainsoni (Fraiha \& Ward, 1974)

L. spp.

Subgenus Nyssomyia Barretto, 1962

Lutzomyia anduzei (Rozeboon, 1942)

L. flaviscutellata (Mangabeira, 1942)

L. richardwardi Ready \& Fraiha, 1981

L. shawi Fraiha, Ward \& Ready, 1981

L. umbratilis Ward \& Fraiha, 1972

L. yuilli yuilli Young \& Porter, 1972

Subgenus Psathyromyia Barretto, 1962

TABLE

Sandflies collected on human bait in Samuel Ecological Station, in Porto Velho Municipality, Rondônia State Brazil October-December 1990 and May-July 1991

\begin{tabular}{|c|c|c|c|c|c|c|}
\hline & \multirow{2}{*}{\multicolumn{2}{|c|}{$\begin{array}{c}\text { Ground } \\
\text { level }\end{array}$}} & \multicolumn{2}{|c|}{$20 \mathrm{~m}$ above } & \multirow{2}{*}{\multicolumn{2}{|c|}{ Total }} \\
\hline & & & ground & level & & \\
\hline & No. & $\%$ & No. & $\%$ & No. & $\%$ \\
\hline 1. L. richardwardi & 209 & 29.9 & 56 & 12.7 & 265 & 23.2 \\
\hline 2. L. umbratilis & 14 & 2.0 & $214^{a}$ & 48.5 & 228 & 19.9 \\
\hline 3. L. c. carrerai & 197 & 28.1 & - & - & 197 & 17.2 \\
\hline 4. L. y. yuilli & 17 & 2.4 & 106 & 24.0 & 123 & 10.8 \\
\hline 5. L. (Psychodopygus) spl & 118 & 16.9 & - & - & 118 & 10.3 \\
\hline 6. L. (Psychodopygus) sp2 & 86 & 12.2 & 3 & 0.7 & 89 & 7.8 \\
\hline 7. L. gomezi & - & - & 33 & 7.5 & 33 & 2.9 \\
\hline 8. L. davisi & 22 & 3.1 & 1 & 0.2 & 23 & 2.0 \\
\hline 9. L. ayrozai & 15 & 2.1 & - & - & 15 & 1.3 \\
\hline 10. L. evangelistai & - & - & 10 & 2.3 & 10 & 0.9 \\
\hline 11. L. shannoni & 1 & 0.1 & 8 & 1.9 & 9 & 0.8 \\
\hline 12. L. lainsoni & 5 & 0.7 & 2 & 0.4 & 7 & 0.6 \\
\hline 13. L. dendrophila & - & - & $6^{b}$ & 1.4 & 6 & 0.5 \\
\hline 14. L. amazonensis & 5 & 0.7 & - & - & 5 & 0.4 \\
\hline 15. L. shawi & 5 & 0.7 & - & - & 5 & 0.4 \\
\hline 16. L. flaviscutellata & 3 & 0.4 & - & - & 3 & 0.3 \\
\hline 17. L. anduzei & 2 & 0.3 & - & - & 2 & 0.2 \\
\hline 18. L. claustrei & 2 & 0.3 & - & - & 2 & 0.2 \\
\hline 19. L. punctigeniculata & 1 & 0.1 & 1 & 0.2 & 2 & 0.2 \\
\hline 20. L. braziliensis & - & - & 1 & 0.2 & 1 & 0.1 \\
\hline Total & 702 & 100.0 & 441 & 100.0 & 1143 & 100.0 \\
\hline $\begin{array}{l}\text { Spent hours } \\
\text { Spent days }\end{array}$ & $\begin{array}{r}112 \\
56\end{array}$ & & & & & \\
\hline
\end{tabular}

$a$ : including $2 \delta$ ot.

$b$ : including $1 \delta$. 
Lutzomyia punctigeniculata (Floch \& Abonnenc, 1944)

L. shannoni (Dyar, 1929)

L. dendrophila (Mangabeira, 1942)

Subgenus Lutzomyia França, 1940

Lutzomyia evangelistai Martins \& Fraiha, 1971

L. gomezi (Nitzulescui, 1931)

Group Aragaoi Theodor, 1965

Lutzomyia braziliensis (Costa Lima, 1932)

Table shows that these following species were predominant, using human bait: $L$. richardwardi $(23.2 \%)$, L. umbratilis $(19.9 \%)$ and $L$. C. carrerai $(17.2 \%)$, corresponding to $63 \%$ of the collected sandflies.

Antropophily of species - Table shows all the species collected biting man. L. richardwardi and $L$. umbratilis were the most abundant anthropophilic sandfly species during the captures. $L$. richardwardi was the most active at ground level $(29.9 \%)$, while with $L$. umbratilis was more common at $20 \mathrm{~m}(48.5 \%)$.

Stratification studies - Figure shows the occurrence of species which are more frequent at ground level compared with the canopy. Collection of species, $L$. c. carrerai $(100.0 \%)$, L. (Psychodopygus) spl $(100.0 \%)$ and $L$. (Psychodopygus) sp2 (96\%) occurred predominantly at ground level. Although $L$. richardwardi was more frequent $(79 \%)$ at this level, it was taken in the canopy $(21 \%)$. Only three species were found in high numbers in the canopy: L. gomezi $(100.0 \%)$, L. umbratilis $(94 \%)$ and L. y. yuilli $(86 \%)$.

These results suggest the high frequency of subgenus Psychodopygus species on the ground floor, while the Subgenus Nyssomyia was predominantly, in the canopy, with the exception of $L$. richardwardi.

\section{DISCUSSION}

The studies performed at the Samuel Ecological Station have indicated the presence of 20 species of sandflies, with a predominance of three species: L. richardwardi, L. umbratilis and $L$. C. carrerai. L. umbratilis and $L$. flaviscutellata are confirmed as being important vectors of cutaneous leishmaniasis in North Brazil (Lainson \& Shaw, 1968; Lainson et al., 1979).
Some studies on sandflies from Rondônia State have contributed interesting results (Martins et al., 1965; Biancardi et al., 1982).

Sandfly surveys carried out in the past in Rondônia State, paid no attention to the biology of the species. Martins et al. (1965) performed captures and identified 40 species and indicated that $L$. shannoni, $L$. flochi and $L$. wilsoni were the most frequent. In 1978 Martins et al. cited two more species of the genus Lutzomyia, being the total number of species to 42 . Biancardi et al. (1982) collected 62 species and showed that $L$. antunesi, L. yuilli and $L$. davisi constituted about $42 \%$ of their collection. These authors cite 36 species that had not previously been reported in Rondônia State and suggested the difference was due to collecting methods.

In the present work, we report $L$. shawi and L. punctigeniculata for the first time in Rondônia State. We are considering L. (Psychodopygus) spl species as belonging to squamiventris series and $L$. (Psychodopygus) $\mathrm{sp} 2$ as species of the guyanensis series, because we collected only females, and the studies of these series are confused up to now.

Biancardi et al. (1982) worked near to the Samuel Ecological Station and collected males of $L$. chagasi and $L$. complexa: the females were grouped as $L$. (Chagasi) $\mathrm{sp}$. because they can not be separated morphologically. In the same area these authors reported L. guyanensis, however Young \& Ducan (1992) report the distribution of this species as restrict to French Guyana, thus suggesting that the L. guyanensis male in described could be $L$. corossoniensis, $L$. geniculata or L. dorlinsis.

There are few studies about stratification of sandflies in the Amazon region. In Central Amazônia, Arias \& Freitas (1977) using human bait and horse bait at ground level, and the human bait in the canopy, foud $L$. squamiventris (cited as L. maripaensis), L. davisi, L. ayrozai and L. umbratilis (cited as $L$. anduzei Floch \& Abonnenc) as the predominant species. $L$. squamiventris was the most common species taken off man and horse on the ground level, while $L$. umbratilis was predominant at $15 \mathrm{~m}$ above ground floor.

Arias \& Freitas (1982) used CDC light traps at $1 \mathrm{~m}$ and $15 \mathrm{~m}$ height in the Ducke Forest Reserve, near to Manaus City, in Central 
Amazon. They observed $L$. anduzei and $L$. umbratilis as the predominant species $-70.6 \%$. It was verified that $L$. anduzei, $L$. rorotaensis, L. ruii, L. umbratilis and $L$. squamiventris were abundant at one meter. $L$. anduzei and $L$. umbratilis were dominant at $15 \mathrm{~m}$ above the ground floor.

Although the different methods of capture may influence the results, and the ecological conditions may cause some modification to the sandfly population, in general, we observed the predominance of subgenus Psychodopygus and Nyssomyia at ground level and in the canopy, respectively, as was reported by Arias et al. (1982) and Ready et al. (1986).

\section{ACKNOWLEDGEMENTS}

To Dr Eunice A. B. Galati, São Paulo University, and Dr Paul Ready, The Natural History Museum, for their critical reading the manuscript.

\section{REFERENCES}

ARIAS, J. R. \& FREITAS, R. A., 1977. Flebótomos da Amazônia Central do Brasil. 1. Resultados obtidos das capturas feitas em iscas humanas e equinas (Diptera: Psychodidae). Acta Amazônica, 7: 507 527.

ARIAS, J. R. \& FREITAS, R. A., 1982. On the vectors of cutaneous leishmaniasis in the Central Amazon of Brazil. 3. Phlebotomine sandfly stratification in a terra firme forest. Acta Amazônic:a. 12: 599-608.

BIANCARDI, C. B.; ARIAS, J. R.; FREITAS, R. A. \& CASTELLON, E. G., 1982. The known geographical distribution of sandflies in the State of Rondonia,
Brazil (Diptera: Psychodidae). Acta Amazonica, 12: 167-179.

ELETRONORTE/SONDOTÉCNICA, 1988. Estudos de impacto ambiental (E.I.A.). UHE Samuel V. 1-3.

ELETRONORTE, 1990. Plano de Manejo. Departamento de Estudos de Efeitos Ambientais, Divisão de Ambiente Terrestre.

LAINSON, R., 1983. The American leishmaniasis: some observations on their ecology and epidemiology. Trans. R. Soc. Trop. Med. Hyg., 77: 569-596.

LAINSON, R. \& SHAW, J. J., 1968. Leishmaniasis in Brazil. I. Observations on enzootic rodent leishmaniasis - incriminating of Lutzomyia flaviscutellata (Mangabeira) as the vector in the lower Amazonian basin. Trans. R. Soc. Trop. Med. Hyg., 62: 385-395.

LAINSON, R.; SHAW, J. J.; WARD, R. D.; READY, P. D. \& NAIFF, R. D., 1979. Leishmaniasis in Brazil. XIII. Isolation of Leishmania from armadillos (Dasypus novencintus) and observations on the epidemiology of cutaneous leishmaniasis in north Pará State. Trans. R. Soc. Trop. Med. Hyg., 73: 239-242.

MARTINS, A. V.; FALCÃO, A. L. \& SILVA, J. R., 1965. Notas sobre os flebótomos do território de Rondônia, com a descrição de seis espécies novas. Rev. Brasil. Biol., 25: 1-20.

MARTINS, A. V.; WILLIAMS, P. \& FALCÃO, A. L., 1978. American Sandflies (Diptera: Psychodidae, Phlehotominae). Rio de Janeiro. Academia Brasileira de Ciências, IV + 195 p.

READY, P. D.; LAINSON, R; SHAW, J. J. \& WARD, R. D., 1986. The ecology of Lutzomyia umbratilis Ward \& Fraiha (Diptera: Psychodidae), the major vector to man of Leishmania braziliensis guyanensis in the north-eastern, Amazonian Brazil. Bull. ent. Res., 76: 21-46.

YOUNG, D. G. \& DUNCAN, M. A., 1992. Guide to the identification and geographic distribution of Lutzomyia sandflies in Mexico, the west Indies, Central and South America (Diptera: Psychoddiae). Mem. of the America Entomological Institute, in press. 